\title{
EDUCAÇÃO E EMANCIPAÇÃO EM T. W. ADORNO: CONTRIBUIÇÕES PARA A FORMAÇÃO DE PROFESSORES
}

\author{
EDUCACIÓN Y EMANCIPACIÓN EN T. W. ADORNO: CONTRIBUCIONES \\ PARA LA FORMACIÓN DE PROFESORES
}

\section{EDUCATION AND EMANCIPATION IN T. W. ADORNO: CONTRIBUTIONS TO THE FORMATION OF TEACHERS}

\author{
Luciana ZAMBEL ${ }^{1}$ \\ Luiz Antônio Nabuco LASTÓRIA ${ }^{2}$
}

Resumo: Para Adorno, a educação tem por objetivo principal a emancipação humana. Emancipar, como veremos, significa criar condições para que cada um possa viver livremente, e assim ser capaz de desenvolver todas as suas potencialidades. Mas, se por um lado tais objetivos se apresentam até mesmo para nós com certa obviedade, por outro, como apontará Adorno, sua efetivação encontrará caminhos pedregosos. Diante de tais questões, o artigo visa apresentar em que medida é possível construir uma educação voltada para a emancipação, destacando, sobretudo, o papel dos professores nesse processo.

PALAVRAS-CHAVE: Educação. Emancipação. Professores.

RESUMEN: Para Adorno, la Educación tiene como objetivo principal la emancipación humana. Emancipar, como veremos, significa crear condiciones para que cada uno pueda vivir libremente, y así ser capaz de desarrollar todas sus potencialidades. Sin embargo, si por una parte dichos objetivos se presentan incluso para nosotros con cierta obviedad, por otra, como apuntará Adorno, su efectuación encontrará caminos difíciles. Ante estas cuestiones, el artículo presenta en qué medida es posible construir una educación dirigida a la emancipación, destacando, sobre todo, el papel de los profesores en ese proceso.

PALABRAS CLAVE: Educación. Emancipación. Profesores.

ABSTRACT: For Adorno, education is primarily engaged in human emancipation. Emancipate, as we shall see, it means creating conditions so that everyone can live freely, and thus be able to develop their full potential. But, if on the one hand these goals are presented even to us with a certain obviousness, on the other hand, as will point Adorno, its effectiveness will find difficult or hand way. Faced with such questions, the article presents to what extent it is possible to build an education for empowerment, emphasizing, above all, the role of teachers in this process.

KEY WORDS: Education. Emancipation. Teachers.

\footnotetext{
1 Mestranda em Educação escolar pela Universidade Estadual Paulista Júlio de Mesquita Filho UNESP/Araraquara.

${ }^{2}$ Professor Doutor Livre Docente vinculado ao Departamento de Psicologia da Faculdade de Educação da Universidade Estadual Paulista Júlio de Mesquita Filho - UNESP/Araraquara.
} 


\section{Introdução}

A questão da educação é analisada para T. W. Adorno, sobretudo a partir de meados do século XX, especialmente entre as décadas de 50 e 60. Período pós Segunda Guerra, cujos sintomas ainda se faziam fortemente presentes na sociedade. A guerra, entendida como sinônimo da mais profunda incapacidade humana ao diálogo, significará para ele a efetivação da barbárie. Trata-se, como veremos, de momentos extremos em que as singularidades serão negadas em prol de projetos universais de poder e dominação.

Olhar criticamente para o passado e ser capaz de compreender o que noutros momentos foi determinante para que barbáries como a de Auschwitz fossem possíveis, constitui, na visão adorniana, a máxima mais urgente para a educação. "A exigência que Auschwitz não se repita é a primeira de todas para a educação" (ADORNO, 1995a, p. 177). Mas, o que significa dizer "para que Auschwitz não se repita", ou ainda, em que medida a educação poderia eliminar tais barbáries? Questões desafiadoras, sobretudo se considerarmos que muitos dos elementos que levaram a elas ainda continuam presentes na sociedade, como, por exemplo, os discursos autoritários e as constantes tentativas de uniformização dos comportamentos conduzidos; em especial, por aquilo que Adorno e Horkheimer denominaram de "Indústria Cultural" na obra Dialética do Esclarecimento, publicada em 1947.

A indústria cultural, como veremos, constituirá um dos principais elementos que a todo o momento tentará impossibilitar ao indivíduo o pensamento crítico. Ao representar o mundo, esta, impedirá o verdadeiro encontro entre o indivíduo e o mundo, criando, desse modo, uma "pseudoindividualidade". A indústria cultural determinará aquilo que o indivíduo deverá ou não consumir, como também aquilo que ele deverá ou não pensar. Ela, desse modo, controla tanto o bolso quanto o pensamento. "Na indústria, o indivíduo é ilusório não apenas por causa da padronização do modo de produção. Ele só é tolerado na medida em que sua identidade incondicional com o universal está fora de questão" (ADORNO; HORKHEIMER, 1985, p. 128).

Na sociedade administrada, pensar criticamente e de modo autônomo, cada vez mais se torna urgente. Eis aí o grande desafio da educação: possibilitar o pensamento crítico e desenvolver a autonomia do indivíduo. Problemáticas que devem ser enfrentadas pela educação, caso contrário, seu objetivo emancipatório se restringirá exclusivamente ao campo do utilitarismo. Para abordar tais questões este artigo tomará 
como fonte, sobretudo, as entrevistas e debates sobre educação realizadas por Adorno entre os anos de 1959 a 1969, com Hellmut Becker e Gerd Kadelbach, numa rádio em Hessen, na Alemanha. ${ }^{3}$

\section{T.W. Adorno e as primeiras décadas do século XX}

Theodor W. Adorno nasceu na cidade alemã de Frankfurt amMainem em 1903 e morreu em 1969 na cidade de Visp, na Suíça. Com uma ampla e profunda formação em diversos campos do conhecimento, abrangendo da filosofia à música, ele viveu e escreveu suas obras em meio a dois episódios catastróficos do século XX: a primeira e a segunda guerra mundial. Na primeira guerra ele se encontrava com um pouco mais de 10 anos de idade, e, por isso, certamente pouco compreendia sobre aquilo que se passava em seu país. A guerra como sabemos não começa com o conflito real, nem mesmo termina quando o último canhão dispara a última bala. Mais que isso, a guerra, tanto antes quanto depois, deixa os seus vestígios, seus rastros de dor e outras mazelas constantes.

Nesse cenário, já nos primeiros anos da década de 20, marcada por instabilidades seja no campo social, político e econômico, a esquerda na Alemanha encontrava-se, a princípio, e de acordo com Duarte (2003, p. 13), na seguinte situação: “ou apoiava os social-democratas, no poder desde o início da República da Weimar, ou aceitava a liderança de Moscou e fazia oposição à social democracia (...)"4. No entanto, com a presença de Felix Weil que acabara de terminar o seu doutorado em ciência política na Universidade de Tübingen, se coloca uma terceira alternativa para a esquerda. Assim, já no verão de 1922 em Ilmenau, este organiza a "Primeira semana marxista do trabalho", evento que teve como tema central "A importância do papel do intelectual" e contou com a participação de importantes intelectuais, como, por exemplo: Georg Lukács, Karl Korsch, Friederich Pollock e Karl Wittfogel. ${ }^{5}$

A partir do primeiro encontro promovido por Weil sucedeu a pretensão de se tornar constantes os debates mediante a criação de um instituto de pesquisa em 1923, o que mais tarde ficou conhecido como Instituto de Pesquisa Social (Institut zur

${ }^{3}$ ADORNO, W. Theodor. Educação e emancipação. Tradução: Wolfgang Leo Maar. Rio de Janeiro, $3^{\text {a }}$ edição, Editora: Paz e Terra, 1995a, p. 8.

${ }^{4}$ DUARTE, Rodrigo. Teoria crítica da indústria cultural. Belo Horizonte: Editora UFMG, 2003, p. 13.

${ }^{5}$ Ibid, p. 14. 
Sozialforschungen) ou ainda "Escola de Frankfurt", cuja primeira gestão ficou à cargo de K. Grünberg. ${ }^{6}$

Entretanto, mesmo reunindo intelectuais de diversas áreas do saber, os primeiros anos do Instituto foram marcados por intensos debates internos sobre os rumos que deveriam tomar naquela conjuntura socioeconômica e política. Como lembra M. Nobre (2008, p. 36), desde a ascensão do nazismo nos primeiros anos da década de 30 até meados de 40, com sua queda, o Instituto teve à sua frente, entre os anos de 1930 a 1958, Max Horkheimer; e, posteriormente, Theodor W. Adorno. "De 1933 a 1950, o Instituto de Pesquisa Social foi obrigado a se exilar sucessivamente na Suíça (1933), na França (1934) e, por fim, nos EUA (1934 - 1950)" (NOBRE, 2008, p. 36).

Apesar das inúmeras mudanças, tanto na estrutura física, como na postura intelectual que assumira, o Instituto teve em Adorno e Horkheimer, sobretudo nas décadas de 30 e 40, presença importante no âmbito do desenvolvimento da pesquisa social. No que diz respeito aos trabalhos de Horkheimer, eles resultaram, em especial, em dois textos, nos anos de 1936 e 1937, que são respectivamente: "Egoísmo e movimentos de libertação. Para a antropologia da era burguesa" e "Teoria tradicional e teoria crítica". Tais publicações, de acordo com Duarte (2003, p. 39), podem ser vistas como antecipação das questões que somente irão aparecer na Dialética do Esclarecimento, dez anos depois, em 1947, em parceria com as pesquisas sobre cultura de massa de Adorno. Sobre a importância das pesquisas desenvolvidas a partir do Instituto, assinala Nobre (2008, p. 35) que em "Teoria tradicional e teoria crítica" aparece pela primeira vez a expressão "teoria crítica" em contraposição à teoria tradicional, apesar de que, segundo ele, o próprio Horkheimer ter afirmado ser a teoria crítica o resultado do "movimento intelectual e político de compreensão e transformação da sociedade que já existia muito antes de ele lhe dar esse nome e de confrontá-lo com outros ramos de pensamento que ele denominou teoria tradicional" (NOBRE, 2008, p. 35).

Com efeito, no que diz respeito à educação, a teoria crítica visa submeter o próprio sistema educacional ao âmbito da crítica, isto é: perguntar em que medida a própria educação estaria proporcionando a emancipação dos indivíduos. A teoria crítica permite, portanto, que se indague tanto acerca do papel histórico desempenhado pelos

${ }^{6}$ Ibid, p. 15. 
sistemas educacionais, como também pelo que caberia a cada indivíduo que, direta ou indiretamente está envolvido com as práticas educativas.

\section{Semiformação e formalização: a educação na era da indústria cultural}

Conforme Adorno, a semiformação é o resultado de certo tipo de formalização da educação. Noutras palavras: ocorre quando a educação deixa de ser capaz de esclarecer - no sentido kantiano - os educandos, servindo, desse modo, aos propósitos da indústria cultural. Essas e outras questões foram amplamente discutidas por Adorno durante os anos entre 1959 e 1969 por meio de um ciclo de conferências concedidas pelo filósofo a uma rádio na cidade de Hessen, na Alemanha.

Para abordar essas conferências, utilizaremos a tradução para o português realizadas por Wolfgang Leo Maar e reunidas com o título "Theodor W. Adorno Educação e emancipação."7 Nestas conferências, Adorno assinala que a educação no contexto da semiformação e da formalização proporcionada pela indústria cultural tem uma difícil tarefa. Diz ele:

A seguir, e assumindo o risco, gostaria de apresentar a minha concepção inicial de educação. Evidentemente não a assim chamada modelagem de pessoas, porque não temos o direito de modelar pessoas a partir do seu exterior; mas também não a mera transmissão de conhecimentos, cuja característica de coisa morta já foi mais do que destacada, mas a produção de uma consciência verdadeira. Isto seria inclusive da maior importância política; sua ideia se é permitido dizer assim, e uma exigência política. Isto é: uma democracia com o dever de não apenas funcionar, mas operar conforme seu conceito demanda pessoas emancipadas. Uma democracia efetiva só pode ser imaginada enquanto uma sociedade de quem é emancipada (ADORNO, 1995a, p. 141-142).

Para Adorno, a educação jamais pode fixar-se em modelos pré-estabelecidos, isto é, em modelos de ensino. Essa modelagem, de acordo com ele, formaliza a educação, o que a impede de se desenvolver, e, portanto, de tornar-se crítica de si mesma. Quando a escola não está aberta para refletir-se criticamente, ela se comporta tal como as fábricas, colocando-se distante do aluno e tratando estes como se fossem “objetos". Esse "modelo" de educação que se pauta pela formalidade impede ao aluno de emancipar-se. Trata-se de uma visão educacional pautada por certo tipo de

${ }^{7}$ ADORNO, W. Theodor. Educação e emancipação. Tradução: Wolfgang Leo Maar. Rio de Janeiro, $3^{\text {a }}$ edição, Editora: Paz e Terra, 1995a. 
autoritarismo. A partir dele, o aluno é visto como aquele que não sabe, portanto, um ser passivo; e, o professor, como àquele que tem a posse do saber, ou seja, um ser ativo.

Para Adorno, a educação possui inevitavelmente um caráter político. Espaços educacionais, como, por exemplo, as escolas, não podem permanecer centradas em suas supostas verdades de modo a impedir o debate crítico da situação social vigente. Ao contrário, enquanto espaços educacionais que são necessitam repensar constantemente a si mesma, ou seja, submeterem-se à própria crítica. Quando a escola é capaz de refletir sobre o seu próprio fazer educacional, ela se torna capaz de restringir as possibilidades de que atos bárbaros venham ocorrer.

Adorno reconhece ainda os riscos de que Auschwitz volte a se repetir, sobretudo, porque, segundo ele, àquelas situações que proporcionaram tamanha barbárie ainda estão presentes na sociedade contemporânea, como por exemplo, certa ordem de discursos autoritários. Para o frankfurtiano, enquanto perpetuarem a presença de discursos autoritários e as tentativas de "uniformizar" a sociedade a partir de uma única visão de mundo, Auschwitz continuará sendo um espectro. E, devemos ter em conta que os discursos explícitos ou implicitamente autoritários, infelizmente, ainda se fazem presente em ambientes escolares. Esses discursos revelam uma tendência de formalização da sociedade, herança dos regimes totalitários.

No entanto, a paixão pela formalização, hoje por toda parte predominante, em geral omite que ela tem ao mesmo tempo a tendência a em grande medida se distanciar do interesse específico pela sociedade concreta vigente. Pode-se mesmo afirmar que toda a questão da formalização depende de sua parte do crescente caráter formal, isto é, do caráter funcional abstrato da sociedade, mediante o qual a formalização aparece menos como uma meta ou um ideal, mas antes como problema de sociologia. Naturalmente a formalização possui laços estreitos com a instrumentalização, ou seja, com a crença de que a constituição de instrumentos de pesquisa altamente elaborados garante por si a objetividade (ADORNO, 2008, p. 168).

A formalização faz com que os alunos vejam o mundo somente a partir daquilo que a escola julga ser o verdadeiro, enquanto instituição onde se concretizam as políticas do Estado para a educação, destruindo a capacidade imaginativa tão importante para o desenvolvimento da criança. Se perseguir tão somente esse formalismo a escola se colocará como a detentora da verdade, e o aluno como o receptor; a sala de aula, por sua vez, se apresentará como espaço de afirmação de verdades e não como lugar de construção e desconstrução de ideias. Imbuída de uma perspectiva técnica a escola passa a funcionar como reprodutora do sistema vigente; como instrumento de 
massificação e manipulação, mas não como produtora de uma consciência verdadeira, tal como sublinha Adorno.

Ao se pautar pela repetição de modelos pré-estabelecidos de educação, a escola aniquila o desenvolvimento da subjetividade dos alunos, impedindo-lhes o acesso à realidade por conta própria. Como ocorre no âmbito da indústria cultural, a escola, acreditando garantir proteção do aluno, se coloca como àquela que tem o dever de representar a realidade. Ao assim proceder, a escola cria imperativos afirmativos em que a dúvida não aparece como o caminho para a busca da verdade, mas tão somente como algo a ser evitado. Duvidar adquire a significação de que algo possa não estar encaixado nessa poderosa maquinaria ideológica representada pela indústria cultural na atualidade.

Como assinalaram enfaticamente Adorno e Horkheimer na obra Dialética do Esclarecimento, a modernidade trouxe consigo uma concepção de saber marcada exclusivamente pela dominação. Portanto, tanto a semiformação quanto a padronização são geradas pela própria indústria cultural, para que os indivíduos ao consumirem determinados produtos, se esqueçam de que são eles que, na verdade, são também consumidos. Na sociedade em que prepondera a semiformação e a formalização é o produto que assume o papel que deveria ser o do consumidor. Há, na realidade, uma inversão na relação sujeito e objeto. O consumidor passa a ser objeto do consumo e o produto, o sujeito. Isto ocorre na medida em que é este último que determina àquele.

$\mathrm{Na}$ indústria, o indivíduo é ilusório não apenas por causa da padronização do modo de produção. Ele só é tolerado na medida em que sua identidade incondicional com o universal está fora de questão. Da improvisação padronizada no jazz até os tipos originais do cinema, que têm de deixar a franja cair sobre os olhos para serem reconhecidos como tais, o que domina é a pseudo-individualidade. O individual reduz-se à capacidade do universal de marcar tão integralmente o contingente que ele possa ser conservado como o mesmo (ADORNO; HORKHEIMER, 1985, p. 128).

Para os autores da Dialética de Esclarecimento, a propaganda na era da indústria cultural torna-se a grande mola ideológica do sistema, impedindo o consumidor de pensar. Sempre visando adequar sua linguagem ao público, a propaganda funciona como meio eficaz de expansão dos interesses burgueses. Trata-se de uma linguagem universalizante e meticulosamente fabricada para suprir todas as possíveis lacunas ou dúvidas presentes na cabeça dos potenciais consumidores em relação ao produto ofertado, e, desse modo, servir aos interesses do sistema econômico. A dúvida não faz parte do negócio, os rótulos dos produtos devem dizer tudo àquilo que o consumidor 
deve saber. Nesse sistema, até mesmo a voz do locutor de rádio precisa se fazer compreender: "O locutor de rádio não precisa mais falar de maneira pomposa. Aliás, ele seria esquisito, caso sua entonação se distinguisse da entonação de seu público ouvinte" (ADORNO; HORKHEIMER, 1985, p. 138).

Essa adequação milimétrica dos produtos ao consumidor é o que ocorre também, e de modo ainda mais perverso, de acordo com Adorno, mediante os meios de comunicação de massa, sobretudo a televisão. Adorno, apesar de não ser contrário à televisão, assinala que o que lhe preocupa é o uso desta enquanto divulgadora de informações equivocadas. Ainda assim, ajuíza o filósofo:

Nesta medida gostaria de chamar a atenção para que não se veja a televisão, que constitui somente um momento no sistema conjunto da cultura de massa dirigista contemporânea orientada numa perspectiva industrial, a que as pessoas são permanentemente submetida em qualquer banca de jornal, em incontáveis situações da vida, de modo que a modelagem conjunta da consciência e do inconsciente só pode ocorrer por intermédio da totalidade desses veículos de comunicação de massa (ADORNO, 1995a, p. 88).

Para Adorno, aos produtos da indústria cultural veiculados pela televisão não se pode atribuir o conceito de formação, entendida enquanto Bildung. Para ele, tal expressão é muito complexa para se referir àquilo que tais meios se propõem. Entende que o conceito de informação seria mais adequado para expressar o que tais meios divulgam.

Na visão adorniana, a televisão é parte da sistemática mercadológica, ou melhor: o seu interesse não se circunscreve à formação no sentido de permitir ao indivíduo que, de fato, reflita. Ao contrário, o seu interesse maior é a venda de produtos. Para o filósofo, portanto, não podemos esquecer que em tempos de indústria cultural os produtos são cuidadosamente planejados para adequarem-se às possíveis necessidades imediatas dos consumidores, e, com as mensagens televisivas, não ocorre algo diferente. A televisão é parte da indústria cultural e a realização de suas metas pressupõe, tal qual os demais meios de comunicação constitutivos dessa mesma indústria, a padronização e a manipulação sistemática dos indivíduos. As retóricas publicitárias que constituem em grande medida os discursos propagados por tais meios de comunicação procuram a todo o momento entreter e enredar o indivíduo a tal ponto de neutralizar a capacidade de reflexão deste acerca do que ali se passa. "A repetição cega e rapidamente difundida de palavras designadas liga à publicidade à palavra de ordem totalitária."8 
Adorno está ciente dos desafios que a educação tem pela frente na era da indústria cultural. Nesse sentido, no ensaio "Tempo livre" de 1969, o filósofo faz a seguinte pergunta: "Tempo livre: o que as pessoas fazem com ele?" Respondendo à questão, o frankfurtiano assinala que o tempo livre, outrora era chamado de "ócio", hoje perdeu o seu real sentido. É o que se vê, por exemplo, na programação da televisão em que o chamado "tempo livre" já se encontra, ao contrário, programado. E, desse modo, o tempo de descanso após longas jornadas de trabalho, agora ressurge como tempo colonizado pelas programações ofertadas pela grande indústria da cultura.

Nos tempos atuais em que o próprio "tempo é dinheiro" o que vigora é a lógica da produção. Falar em tempo livre parece soar como sinônimo de "inatividade", ou seja, um desperdício na ótica do sistema, e, nesse sentido, não ter um "hobby" para se “ocupar" no "tempo livre" não é bem visto. A colonização do tempo "livre" efetuada pela indústria cultural impede que o tempo seja, de fato, livre. A esse respeito ilustra o filósofo:

Para esclarecer o problema, eu gostaria de fazer uso de uma pequena experiência pessoal. Em entrevistas e levantamentos de dados, sempre se é questionado sobre o seu "hobby". Quando as revistas ilustradas informam a respeito de algum figurão da indústria cultural, falar dos quais é, por sua vez, a ocupação principal da indústria cultural, poucas vezes perdem o ensejo de relatar algo mais ou menos íntimo sobre os 'hobbies' dos mesmos. Quando me toca essa questão, fico apavorado: Eu não tenho qualquer 'hobby'. Não que eu seja uma besta de trabalho que não sabe fazer consigo mesma nada além de esforçar-se e fazer aquilo que deve fazer. Mas aquilo com o que me ocupo fora da minha profissão oficial é, para mim, sem exceção, tão sério que me sentiria chocado com a idéia de que se tratasse de 'hobbies', portanto, ocupações nas quais me jogaria absurdamente só para matar o tempo, se minha experiência contra todo tipo de manifestações de barbárie - que se tornaram como que coisas naturais - não me tivesse endurecido. Compor música, escutar música, ler concentradamente, são momentos integrais da minha existência, a palavra 'hobby' seria escárnio em relação a elas. (ADORNO,1995b, p. 71-72)

Para Adorno, é preciso analisar porque na sociedade da indústria cultural o "tempo livre" não soa bem. Parece haver um receio por parte da indústria cultural de que nesse "tempo", nessa "válvula de escape", o indivíduo destrua todo o "castelo" de "verdades" montado com muito custo por ela. Impedir que o indivíduo desenvolva sua consciência, que ele exercite sua capacidade de imaginação, de criar a partir dele mesmo as imagens que livremente deseja, é o que a indústria cultural procura realizar. Somente assim: "Os produtos da indústria cultural podem ter a certeza de que até 
mesmo os distraídos vão consumi-los alertamente" (ADORNO; HORKHERMER, 1985, p. 104).

Diante desse cenário de dominação sistemática, portanto, somente uma educação que fuja dos padrões estabelecidos torna-se capaz de ainda proporcionar uma visão crítica acerca do estado de coisas presentes na sociedade atual. Mas, como vimos, esse caminho tem à frente todo o poderio da indústria cultural. E, como veremos a seguir, somente uma educação voltada para a emancipação e que seja capaz de desenvolver a autonomia dos alunos conseguiria se colocar de modo reflexivo diante da sociedade organizada sob a égide indústria cultural. Uma educação em que todos dela participem de modo efetivo; uma educação reflexiva e crítica de si mesma na qual tanto os professores quanto os alunos possam ser os verdadeiros protagonistas.

\section{Educar para a autonomia: a importância dos professores}

Para Adorno, quando a educação não é capaz de possibilitar a autonomia dos indivíduos ela se torna um perigoso instrumento de manipulação. A autonomia, tal como ele a compreende, nos remete ao sentido kantiano do termo ${ }^{9}$; trata-se da condição fundamental para que a reflexão se torne possível. Condição em que cada um mediante a vontade livre seja capaz de realizar suas próprias escolhas. Com efeito, Kant, na terceira seção da Fundamentação da Metafísica dos Costumes (1785), define a vontade como uma ação que deve estar livre das determinações puramente sensíveis. Assim sendo, somente a razão, tal como formulado anteriormente na Crítica da Razão Pura (1781), poderia se colocar como o fundamento das ações que se orientam no sentido próprio da liberdade.

Ter autonomia, portanto, significa, de acordo com Kant, assumir o compromisso com a própria liberdade. Como assevera no texto: Beantwortung der Frage: Wasist Aufklärung? (Resposta a pergunta: O que é Esclarecimento?), de 1784, "preguiça" e "covardia"10 impedem o homem de assumir ao compromisso consigo mesmo. Preferindo a dependência em relação ao outro, o homem jamais conseguirá sair da sua "menoridade".

\footnotetext{
${ }^{9}$ ADORNO, 1995a, p. 125.

${ }^{10}$ KANT. Immanuel. Resposta à pergunta: Que é esclarecimento? Textos seletos. Tradução de Floriano de Sousa Fernandes. Petrópolis, RJ: Vozes, 1985, p. 100.
} 
É tão cômodo ser menor. Se tenho um livro que faz as vezes de meu entendimento, um diretor espiritual que por mim tem consciência, um médico que por mim decide a respeito de minha dieta, etc., então não preciso esforçar-me eu mesmo. Não tenho necessidade de pensar, quando posso simplesmente pagar; outros se encarregarão em meu lugar dos negócios desagradáveis. A imensa maioria da humanidade (inclusive todo o belo sexo) considera a passagem à maioridade difícil e além do mais perigosa, porque aqueles tutores de bom grado tomaram a seu cargo a supervisão dela. Depois de terem primeiramente embrutecido seu gado doméstico e preservado cuidadosamente estas tranquilas criaturas a fim de não ousarem dar um passo fora do carrinho para aprender a andar, no qual as encerraram, mostram-lhes, em seguida, o perigo que as ameaça se tentarem andar sozinhas (KANT, 1985, p. 100-102).

Permanecer na menoridade, portanto, é não querer assumir a própria condição racional, ou seja, é aceitar ser movido pelos costumes e tradições. A autonomia, ao contrário, é sinônimo da liberdade, e, desse modo, permite que os caminhos sejam guiados pela reflexão, e não por quaisquer formas de autoritarismo condicionado.

Desenvolver a autonomia é ser capaz de acabar com os discursos coletivistas (ou individualistas), como se a escola fosse uma fábrica em que todos devessem seguir as ordens do diretor ou do encarregado. Como nos lembra Adorno, um dos riscos que a educação está sujeita, sobretudo nos estabelecimentos de ensino, é a manutenção de discursos coletivistas. Frases ouvidas com muita frequência como as do tipo: "é preciso vestir a camisa da escola", ou ainda, "a escola precisa falar uma só língua" ilustram com precisão tais discursos. Estas práticas discursivas indicam, embora às vezes de modo imperceptível, a tentativa de construção de um único discurso, e, através dele, a padronização de comportamentos, retornando justamente àquilo que foi fundamental para que Auschwitz existisse: “o problema da coletivização.” (ADORNO, 2003, p. 127).

Mas, como é possível na sociedade atual proporcionar-se uma educação voltada à emancipação? Tal questão pode ser efetivada a partir do momento em que a escola distancie-se daquelas práticas autoritárias e daqueles discursos pedagógicos voltados à padronização dos alunos, como se estes fossem peças numa linha de montagem. "Essa ideia educacional da severidade, em que irrefletidamente muitos podem até acreditar, é totalmente equivocada"11. Conforme a perspectiva adorniana, faz-se necessário desconstruir a ideia de que a educação não pode interferir na realidade, como se esta não fizesse parte daquela. A educação tem uma função política altamente importante, como

${ }^{11}$ ADORNO, 2003, p. 128. 
já assinalado anteriormente. Este papel faz com que ela se volte para a destruição das ideologias vigentes e proporcione uma reflexão crítica sobre a própria realidade na qual está inserida. A esse respeito, Adorno (1995a, p. 183) fornece-nos a seguinte ilustração:

Por exemplo, imaginaria que nos níveis mais adiantados do colégio, mas provavelmente também nas escolas em geral, houvesse visitas conjuntas a filmes comerciais, mostrando-se simplesmente aos alunos as falsidades ai presentes; e que se proceda de maneira semelhante para imuniza-los contra determinados programas matinais ainda existentes nas rádios, em que nos domingos de manhã são tocadas músicas alegres como se vivêssemos num "mundo feliz", embora ele seja um verdadeiro horror; ou então que se leia junto com os alunos uma revista ilustrada, mostrando-lhes como são iludidas, aproveitando-se suas próprias necessidades impulsivas; ou então que um professor de música, não oriundo da música jovem, proceda a analises dos sucessos musicais, mostrando-lhes por que um hit da parada de sucessos e tão incomparavelmente pior do que um quarteto de Mozart ou de Beethoven ou uma peça verdadeiramente autentica da nova música.

Apresentar aos alunos como a realidade é construída e quais os verdadeiros interesses que se escondem por detrás de cada produto ou mensagem, é cada vez mais urgente para que a educação possa permitir o desenvolvimento da autonomia do aluno. A educação como vimos na citação anterior precisa apresentar ao aluno o mundo tal como ele é. Noutras palavras, ela jamais pode se furtar de levantar críticas seja em relação à sociedade, seja em relação a ela mesma na condição de parte da sociedade. A escola não pode se fechar em seus muros. "A escola possui uma tendência imanente a se estabelecer como esfera própria da vida e dotada de legislação própria" (ADORNO, 1995a, p. 114).

Ao abrir-se para o debate de ideias, a escola está proporcionando tanto a si mesma quando à própria sociedade o exercício da autonomia. Nas palavras de B. Pucci (1995, p. 51), a educação tem uma função primordial na formação de uma sociedade que "se guie mais pela razão, na luta pela autonomia, pela emancipação". Também para Adorno uma educação que se volte para a emancipação jamais poderia se recusar ao debate de ideais. Aliás, como vimos ao longo deste artigo, foi justamente por meio de tal recusa autoritária que a educação favoreceu a padronização comportamental dos indivíduos, tornando-os frios como são as máquinas.

Ao contrário disso, a educação deve se voltar para a crítica dela mesma, analisando seus métodos e propostas de ensino. Somente trilhando este caminho de autocrítica o professor assumirá o seu protagonismo, na medida em que está diretamente vinculado às práticas em sala de aula. Portanto, disposto aos desafios que o mundo 
apresenta à educação poderá o professor trilhar o caminho da emancipação, e assim será capaz de favorecer a construção de uma sociedade em que o esclarecimento, de fato, se torne a "saída da menoridade" e sinônimo de maior liberdade. Enfim, a partir desta perspectiva formadora, o professor terá condições de realizar aquilo que todos almejam: uma educação para a emancipação.

\section{REFERÊNCIAS}

ADORNO, Theodor W. Dialética do esclarecimento: fragmentos filosóficos. Theodor Adorno, Max Horkheimer; tradução, Guido Antônio de Almeida. Rio de Janeiro: Zahar, 1985 ,

ADORNO, Theodor W. Educação e emancipação. Tradução: Wolfgang Leo Maar. Rio de Janeiro, $3^{\text {a }}$ edição, Editora: Paz e Terra, 1995a.

ADORNO, Theodor W Palavras e sinais: modelos críticos 2. Tradução de Maria Helena Ruschel; supervisão de Álvaro Valls. Petrópolis, RJ: Vozes, 1995 b.

ADORNO, Theodor W Introdução à Sociologia. Tradução: Wolfgang Leo Maar. São Paulo. Editora UNESP, 2008.

DUARTE, Rodrigo. Teoria crítica da indústria cultural. Belo Horizonte. Editora UFMG, 2003. (Humanitas).

GOMES, L. R. Teoria Crítica, Educação e Política. In. Teoria crítica e inconformismo: novas perspectivas. Bruno Pucci; Antônio A. S. Zuin, Luiz A. Calmon Nabuco Lastória (orgs.). Campinas, SP: Autores Associados, 2004.

KANT, Immanuel. Crítica da Razão Pura. Editora: São Paulo, Nova Cultural, 1999.

KANT, Immanuel. Fundamentação da Metafísica dos Costumes. Tradução: Paulo Quintela. Lisboa, Portugal, edições 70, 2007,

KANT, Immanuel. Resposta à pergunta: o que é o esclarecimento? In: Textos seletos. Edição Bilíngue. Tradução do original alemão por: Raimundo Vier e Floriano de Sousa Fernandes. Introdução de Emmanuel Carneiro Leão. Ed. Vozes, $2^{a}$ edição, Petrópolis, 1985.

NOBRE, Marcos. Modelos de Teoria Crítica. In. Curso livre de Teoria Critica. Marcos Nobre (Org.). Campinas, SP, Papirus, 2008. 
NOBRE, Marcos. Max Horkheimer e a teoria crítica entre o Nazismo e o Capitalismo tardio. In. Curso livre de Teoria Critica. Marcos Nobre (Org.). Campinas, SP, Papirus, 2008.

PUCCI, Bruno. Teoria Crítica e Educação. In. Teoria Crítica e educação: a questão da formação cultural na Escola de Frankfurt. Bruno Pucci (org.). Petrópolis, RJ: Vozes; São Carlos, SP: EdUFSCar, 1994.

\section{Como referenciar este artigo}

ZAMBEL, Luciana.; LASTÓRIA, Luiz Antônio Nabuco. Educação e emancipação em T. W. Adorno: contribuições para a formação de professores. Revista IberoAmericana de Estudos em Educação, Araraquara, v. 11, n. 4, p. 2205-2218, 2016. Disponível em: 〈http://dx.doi.org/10.21723/riaee.v11.n4.8794>. E-ISSN: 1982-5587.

Submetido em: julho/2016

Aprovação final em: novembro/2016 